\title{
Investigating the Relationship between Knitted Fabric Porosity and Light Permeability
}

\author{
Manoj Kumar Imrith, Roshan Unmar, and Satyadev Rosunee \\ Department of Applied Sustainability \& Enterprise Development, Faculty of Engineering, University of Mauritius, Réduit, Mauritius \\ Correspondence should be addressed to Manoj Kumar Imrith; manoj.imrith@gmail.com
}

Received 27 July 2016; Accepted 22 September 2016

Academic Editor: Hu Hong

Copyright ( 2016 Manoj Kumar Imrith et al. This is an open access article distributed under the Creative Commons Attribution License, which permits unrestricted use, distribution, and reproduction in any medium, provided the original work is properly cited.

\begin{abstract}
The present paper attempts to investigate the relationship between fabric porosity and light permeability of the knitted structures, namely, rib $1 \times 1$, rib $2 \times 1$, single jersey, and plain structure. The rationale is that pores (in a fabric) would allow light to pass through but at the same time provide a quantitative assessment of the UV light permeability of the knitted fabrics, an indication of the protective capacity of the fabrics against UV radiation. The porosity and corresponding light permeability of the knitted structures were measured after varying the following knitting parameters: stitch length, stitch density, and tension on the machine. Furthermore, this work has enabled the development of an apparatus that can measure the amount of light transmitted through the knitted fabrics. The results generated by the equipment were validated through the use of regression equations.
\end{abstract}

\section{Introduction}

A large volume of the fabric remains occupied by airspaces because of the way in which the yarns and fabric are constructed. This implies that there are a large number of porous areas within a given knitted fabric structure. Therefore, knit fabrics contribute to the comfort qualities of the wearer and have long been preferred for many types of clothing. Over and above comfort, especially in athletic and other outdoor wear, the requirement for UV protection is equally important. Skin problems, owing to UV radiation from the sun, are becoming a major cause for concern and engineered textiles can provide the required degree of protection.

The energy of UV radiation received by a textile can be subdivided into the following three components: the energy reflected, absorbed, and transmitted by the textile product. The latter irradiates the human organism directly. These components are formed by the physical and chemical features of the textile product and also by the structural characteristics such as porosity, fabric thickness, and structure (Hanke et. al., Jędrzejewski et. al., and Gabijelcic et. al.) [1-3]. Light transmitted through the knitted fabric must be minimized during wearing. The main attribute influencing transmission is porosity and this is characterized by the pore size. One of the objectives of the research was to come up with a model that can predict the porosity of simple weft knitted structures using their geometrical details.

Yazaki et al. [4] studied the anisotropic light transmission properties of plain knitted fabric samples using biaxial load and uniaxial load stretch method. The uniaxial load method involved stretching the knitted samples similar to the extension rate along the course and wale direction. Variations in the light transmission factors were noticed as the stitch densities of course and wales altered with Poisson's ratio. The stitch densities of wale and course, the yarn diameter in stretched condition, and Poisson's ratio were used to estimate the light transmission factor. In biaxial load, the samples were lengthened uniformly and they showed matching light transmission factors. The final results show that anisotropic light transmission properties varied accordingly with tensile conditions. Yazaki et al. [5] performed fabric design from result of light transmission of plain woven fabric samples. They developed a light transmission apparatus, which could change light incidence and reception directions. Anisotropy property was observed in the light transmission property since the fabric structures are anisotropy. They finally presented an anisotropic approximation curve and the light 
transmission factor of the fabric was measured based on the crimp theory of Pierce.

Equally, Nazir et al. [6] developed statistical methods to predict the light transmission properties and air permeability of woven cotton fabrics. After production and finishing, the air permeability and light transmission of the fabric samples were determined according to standard test method ASTM D737 and image analysis, respectively. Regression analysis was used to determine the correlation between the two parameters of light transmission and air permeability. Similarly, Haleem et al. [7] studied the relationship between air permeability and light transmission properties of woven fabrics. The air permeability was measured using the established standard test method whereas the light transmission was measured by two methods. In the first method, measurement was based on light transmitted from a back lit fabric using a light sensor and the second method was based on image processing technique which required a digital image of fabric and application of an algorithm to measure the amount of light transmitted. Militky et al. [8] measured the transmission of light through selected woven fabrics on the system LUCIA for image analysis. The porosity of the fabrics was evaluated from construction parameters and realistic fabric geometry modeled. They, then, characterized the fabric porosity by comparison with characteristics of air permeability using regression analysis.

Parmar et al. [9] designed an apparatus to measure the light absorbing/cutting ability of curtains and determine their temperature cutting ability. The apparatus consisted of several light sources, including light, humidity, and temperature detectors. From the tested fabric samples, they found that the light and temperature cutting ability of knitted fabric are lower as compared to black-out curtains and woven fabrics samples. Cui et al. [10] tested the reflection and transmission by ultraviolet-visible-near infrared of woven aramid fabrics, Kevlar 49 and blended Kevlar 49/Nomex. It indicated that aramid fabrics possess good light and thermal protecting properties.

Mikolajczyk and Szmyt [11] investigated the light transmission properties of knitted fabrics. It was stated that lightbarrier property of "fabric cover" of the knitted material is a significant parameter. They also stated that the cover factor of the knitted fabric is a sum of the cover factor of the threads in the background of the chain stitch and the cover factor of the pattern threads going between the wales of the chain stitches. Algaba et al. [12] investigated the effect of fabric porosity on the UPF of summer fabrics. They found that fabric porosity was directly related to the fabric construction parameter that influenced the solar UVR transmission.

Luxography method was used to determine light transmission through fabrics. Photograms were generated directly onto light sensitive paper without the use of any optical devices. Following irradiation development and fixation, the papers were characterized by grey levels in proportion to the light transmission and the results were opposite to the virtual method. It was concluded that there is practically no difference between the transmission of visible light and $\mathrm{UV}$ radiation with respect to the real method measurement and virtual measurement (Bransch-Walczak and Jemielity, Dederko, Dulęba-Majek, and Ullman) [13-16].

\section{Materials and Methods}

2.1. Preparation of the Knitted Samples for Measuring Their Light Permeability. In the experimental part of the study, the knitted specimens were stretched uniformly with the minimum tension as shown in Figure 2. Furthermore, with respect to the knitted samples structural configuration, two centimeters of minimum stretched fabric was required and thus the appropriate template is one with opening size of $10 \mathrm{~cm} \times 10 \mathrm{~cm}$ with the fabric samples cut with an assumed standard card template of $12 \mathrm{~cm} \times 12 \mathrm{~cm}$. Stretching was therefore done up to $14 \mathrm{~cm} \times 14 \mathrm{~cm}$. The samples were overlocked to avoid curling and unraveling of the yarns.

\subsection{Experimental Set-Up for Measuring Light Permeability of} the Knitted Fabrics. To measure the light permeability of the knitted fabrics, an apparatus was designed and constructed as illustrated in Figure 1. The concept of the measurement setup to measure light permeability through the knitted fabrics is related to the factors that a black surface absorbs light and from observation when sunlight is incident on people's clothing. A schematic diagram is also shown in Figure 3. The measurement stand set-up is composed of a tunnel box of black matte walls, inside of which the measuring elements are placed: the source of the light (LED lamp) of 3.84 watts, a frame for placing the sample, and a template to temporarily fix the head (probe) of the digital light intensity meter. The principle consists of a box in which one side is the source of light, the middle is the fabric sample, and its parallel side is the sensor aligned as shown in Figure 4. This method enables quick measurement realization of light permeability through the knitted specimens. Valued advantage is that data of light permeability are obtained and recorded instantly. However, careful manipulation of the knitted fabrics specimen onto the template is required.

The values of light permeability of each knitted sample were measured in terms of lux and the percentage calculated as follows:

$$
\% \operatorname{Lux}=\frac{\text { Lux with sample }(\mathrm{LS})}{\text { Lux without sample }(\mathrm{LW})} \times 100 \%
$$

\section{Test Results and Analysis}

3.1. Lux. This section provides data pertaining to the effects of light intensity on knitting parameters. The light intensity values in terms of lux for the knitted fabrics were obtained using the digital light intensity meter.

The values of light permeability of the fabric specimens are shown in Tables 1 and 2. The value, as anticipated, is dependent on increasing or decreasing the stitch cam thereby obtaining high and low stitch length fabrics. The percentage lux was also calculated. An increase in percentage lux was observed because the fabric becomes looser as the stitch level was increased. 

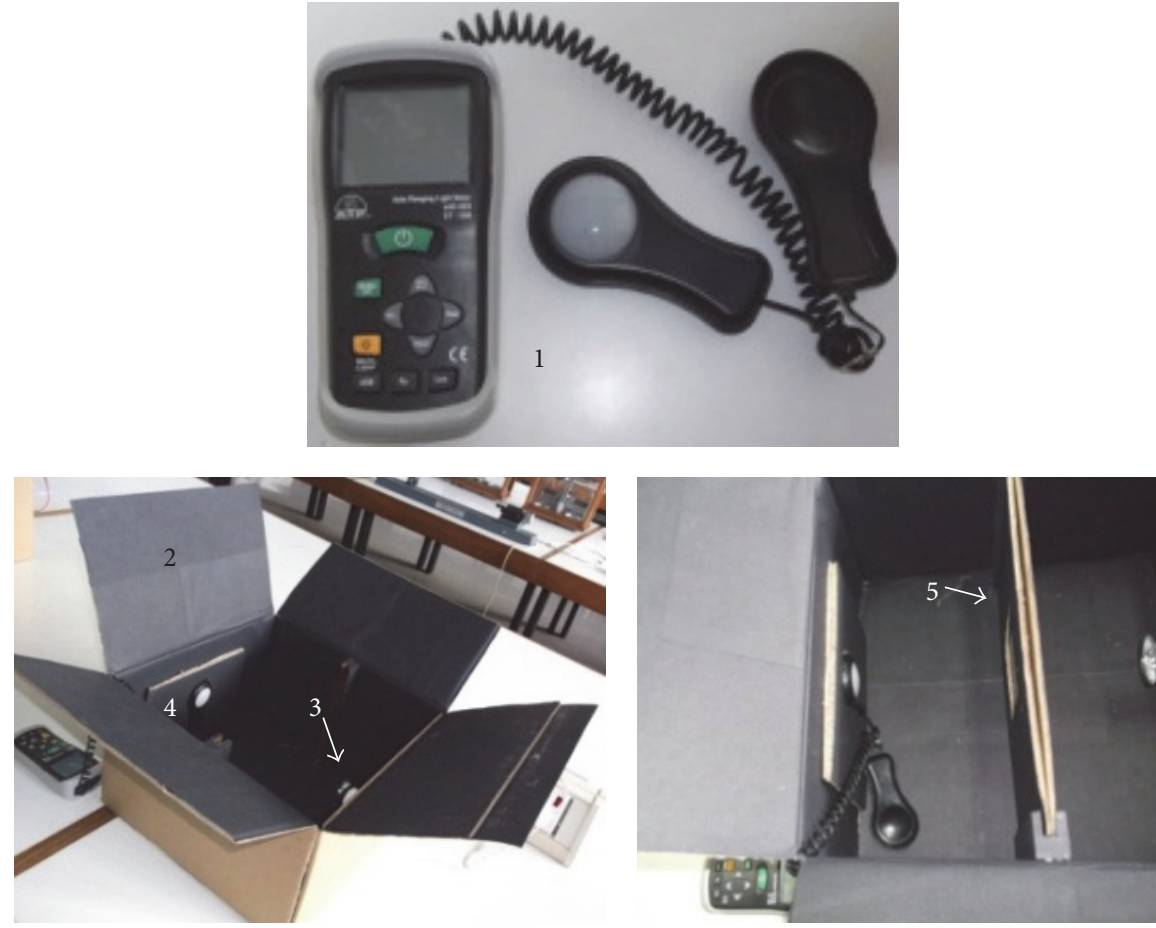

FIGURE 1: Stand set-up constructed for determining the light transmission of knitted fabrics: (1) digital light intensity meter, (2) (box) tunnel, (3) source of light, (4) probe's holder, and (5) sample frame holder.

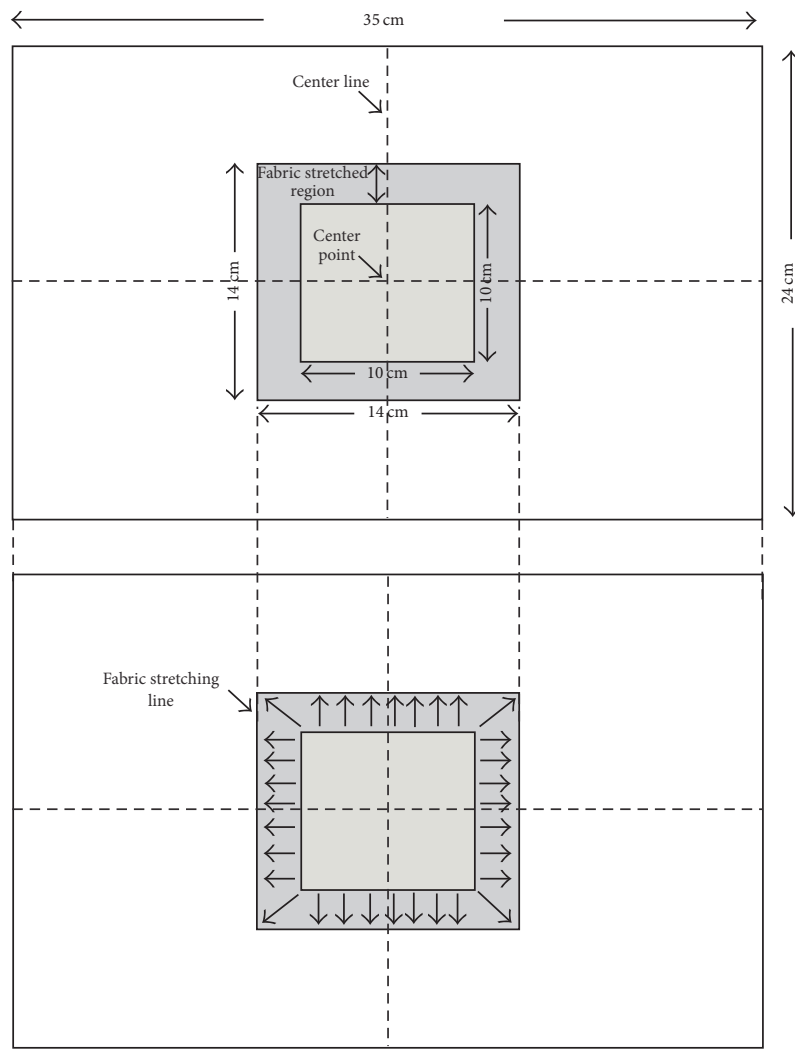

FIGURE 2: Schematic diagram of the frame showing the cut region and the fabric stretched area for the sample.
As shown in Table 3 , an increase in stitch length results in a decrease in the wales per inch, courses per inch, and stitch density. At relatively lower stitch length the fabric is tighter, thus allowing lower light transmission.

According to Table 3, the knitted fabric geometry has a significant influence on the percentage porosity and consequently on the percentage lux, while the results for CKM knit from Table 4 are related to start and in return at the end they are not significant.

\subsection{Results for FKM Samples}

3.2.1. The Effect of Stitch Length on Percentage Lux. There is dependence of knitting parameters such as stitch length on percentage lux. It is evident that the higher the stitch length, the higher the light permeability as shown in Figures 5-8.

Figures 5-8 show that as the stitch length increases, the pores increase, in size, thus allowing more light transmission. Moreover, it can be deduced that it will be more appropriate to use the data for the black mask images due to higher correlation compared with that for the white mask images.

3.2.2. The Effect of Percentage Porosity against Percentage Lux. Figures 9-12 show that an increase in porosity results in an increase in percentage lux. However we may note that, according to the correlation values generated, again, the black mask images show much higher correlation. Black mask images $R^{2}$ values are as follows: plain: $R^{2}=0.871$, rib $1 \times 1$ : $R^{2}=0.828$, rib $2 \times 2: R^{2}=0.694$, and single jersey: $R^{2}=0.789$. 
TABLE 1: Experimental work on light intensity for the knitted structures (FKM samples).

\begin{tabular}{|c|c|c|c|c|c|c|c|c|}
\hline Structures & $\begin{array}{l}\text { Stitch cam } \\
\text { values }\end{array}$ & $\begin{array}{c}\text { Lux without } \\
\text { sample } \\
\text { (LW) }\end{array}$ & $\begin{array}{l}\text { Lux with } \\
\text { sample } \\
\text { (LS) }\end{array}$ & $\begin{array}{c}\text { Percentage lux } \\
(\%)\end{array}$ & $\begin{array}{c}\text { Porosity white } \\
\text { mask images } \\
(\%)\end{array}$ & $\begin{array}{c}\text { Porosity white } \\
\text { mask images } \\
(\%)\end{array}$ & $\begin{array}{c}\text { Stitch } \\
\text { density } \\
\left(K_{s}\right)\end{array}$ & $\begin{array}{c}\text { Stitch } \\
\text { length, } l \\
(\mathrm{~mm})\end{array}$ \\
\hline \multirow{8}{*}{ Plain } & 11 & 389.4 & 37 & 9.52 & 48.2 & 48.3 & 1.96 & 9.4 \\
\hline & 12 & 389.4 & 40 & 10.3 & 49.7 & 49 & 1.6 & 10.5 \\
\hline & 13 & 389.4 & 50 & 12.9 & 50.1 & 49.2 & 1.43 & 10.7 \\
\hline & 14 & 389.4 & 61.4 & 15.8 & 50.5 & 49.7 & 1.21 & 11.4 \\
\hline & 15 & 389.4 & 65.4 & 16.8 & 51.9 & 50.3 & 1.15 & 11.8 \\
\hline & 16 & 389.4 & 68 & 17.5 & 52.2 & 50.4 & 1.07 & 12 \\
\hline & 17 & 389.4 & 70 & 18 & 54.8 & 51.3 & 0.82 & 13.9 \\
\hline & 18 & 389.4 & 73.2 & 18.8 & 55.4 & 51.8 & 0.49 & 14.2 \\
\hline \multirow{8}{*}{ Rib $1 \times 1$} & 11 & 389.4 & 31.8 & 8.2 & 49.1 & 49.2 & 1.95 & 10.5 \\
\hline & 12 & 389.4 & 34.1 & 8.8 & 49.5 & 49.7 & 1.68 & 12.8 \\
\hline & 13 & 389.4 & 40 & 10.3 & 49.6 & 50.5 & 1.58 & 13.8 \\
\hline & 14 & 389.4 & 57 & 14.6 & 49.7 & 50.8 & 1.37 & 15.5 \\
\hline & 15 & 389.4 & 60.2 & 15.5 & 50.1 & 51 & 1.25 & 16 \\
\hline & 16 & 389.4 & 63 & 16.2 & 51.1 & 52.4 & 1.4 & 16.8 \\
\hline & 17 & 389.4 & 65 & 16.7 & 51.2 & 52.5 & 1.14 & 17.3 \\
\hline & 18 & 389.4 & 66.8 & 17.2 & 53.1 & 53.4 & 0.92 & 17.9 \\
\hline \multirow{8}{*}{ Rib $2 \times 1$} & 10 & 389.4 & 31 & 8 & 43.2 & 40.1 & 1.74 & 11.9 \\
\hline & 11 & 389.4 & 32.1 & 8.2 & 45.1 & 42.2 & 1.54 & 12.4 \\
\hline & 12 & 389.4 & 35.4 & 9.1 & 45.2 & 44.1 & 1.32 & 13.8 \\
\hline & 13 & 389.4 & 37.5 & 9.6 & 47.7 & 49.2 & 1.14 & 14.2 \\
\hline & 14 & 389.4 & 41.5 & 10.7 & 48.9 & 49.1 & 1.26 & 15.2 \\
\hline & 15 & 389.4 & 62.1 & 16 & 49.3 & 50.4 & 1.09 & 15.7 \\
\hline & 16 & 389.4 & 66.5 & 17.1 & 50 & 51.4 & 0.99 & 16.3 \\
\hline & 17 & 389.4 & 70 & 18 & 51.3 & 51.6 & 0.92 & 16.7 \\
\hline \multirow{8}{*}{ Single jersey } & 13 & 389.4 & 85.2 & 21.9 & 44.2 & 47.2 & 1.75 & 11.9 \\
\hline & 14 & 389.4 & 88 & 22.6 & 45.3 & 48.1 & 1.67 & 13.1 \\
\hline & 15 & 389.4 & 95.6 & 24.6 & 47 & 48.7 & 1.6 & 13.6 \\
\hline & 16 & 389.4 & 98.2 & 25.2 & 51 & 49 & 1.51 & 14.1 \\
\hline & 17 & 389.4 & 105 & 27 & 51.3 & 49.1 & 1.46 & 14.4 \\
\hline & 18 & 389.4 & 134.2 & 34.5 & 53.5 & 49.6 & 1.27 & 16.6 \\
\hline & 19 & 389.4 & 138.3 & 35.5 & 54.9 & 53.4 & 1.1 & 17.2 \\
\hline & 20 & 389.4 & 142 & 36.5 & 55.2 & 54.1 & 0.74 & 18.6 \\
\hline
\end{tabular}

TABLE 2: Experimental work on light intensity on single jersey (CKM samples).

\begin{tabular}{lccc}
\hline Single jersey sample (CKM) & Lux without sample (LW) & Lux with sample (LS) & Percentage lux (\%) \\
\hline 1 & 389.4 & 44.2 & 11.4 \\
2 & 389.4 & 46.8 & 12 \\
3 & 389.4 & 53.6 & 13.8 \\
4 & 389.4 & 55 & 14.1 \\
5 & 389.4 & 58 & 14.9 \\
6 & 389.4 & 59.5 & 15.2 \\
7 & 389.4 & 64.2 & 16.5 \\
8 & 389.4 & 65.3 & 16.8 \\
\hline
\end{tabular}


TABLE 3: Results of fabric geometry and fabric characteristics of knitted samples, \% lux included (FKM samples).

\begin{tabular}{|c|c|c|c|c|c|c|c|c|}
\hline Structures & $\begin{array}{l}\text { Stitch cam } \\
\text { values }\end{array}$ & $\begin{array}{l}\text { Course per } \\
\text { inch }\left(K_{c}\right)\end{array}$ & $\begin{array}{l}\text { Wales per } \\
\text { inch }\left(K_{w}\right)\end{array}$ & $\begin{array}{l}\text { Stitch density } \\
\left(K_{s}\right)\end{array}$ & $\begin{array}{l}\text { Stitch length, } \\
\quad l(\mathrm{~mm})\end{array}$ & $\begin{array}{l}\text { Percentage } \\
\text { lux }(\%)\end{array}$ & $\begin{array}{c}\text { Porosity white } \\
\text { mask images } \\
(\%)\end{array}$ & $\begin{array}{c}\text { Porosity white } \\
\text { mask images } \\
(\%)\end{array}$ \\
\hline \multirow{8}{*}{ Plain } & 11 & 1.2 & 1.64 & 1.96 & 9.4 & 9.52 & 48.2 & 48.3 \\
\hline & 12 & 1.02 & 1.57 & 1.6 & 10.5 & 10.3 & 49.7 & 49 \\
\hline & 13 & 0.98 & 1.46 & 1.43 & 10.7 & 12.9 & 50.1 & 49.2 \\
\hline & 14 & 0.9 & 1.34 & 1.21 & 11.4 & 15.8 & 50.5 & 49.7 \\
\hline & 15 & 0.88 & 1.31 & 1.15 & 11.8 & 16.8 & 51.9 & 50.3 \\
\hline & 16 & 0.83 & 1.29 & 1.07 & 12 & 17.5 & 52.2 & 50.4 \\
\hline & 17 & 0.72 & 1.15 & 0.82 & 13.9 & 18 & 54.8 & 51.3 \\
\hline & 18 & 0.61 & 0.8 & 0.49 & 14.2 & 18.8 & 55.4 & 51.8 \\
\hline \multirow{8}{*}{ Rib $1 \times 1$} & 11 & 1.1 & 1.77 & 1.95 & 10.5 & 8.2 & 49.1 & 49.2 \\
\hline & 12 & 1.02 & 1.65 & 1.68 & 12.8 & 8.8 & 49.5 & 49.7 \\
\hline & 13 & 0.98 & 1.61 & 1.58 & 13.8 & 10.3 & 49.6 & 50.5 \\
\hline & 14 & 0.91 & 1.5 & 1.37 & 15.5 & 14.6 & 49.7 & 50.8 \\
\hline & 15 & 0.85 & 1.47 & 1.25 & 16 & 15.5 & 50.1 & 51 \\
\hline & 16 & 0.81 & 1.41 & 1.4 & 16.8 & 16.2 & 51.1 & 52.4 \\
\hline & 17 & 0.75 & 1.38 & 1.14 & 17.3 & 16.7 & 51.2 & 52.5 \\
\hline & 18 & 0.7 & 1.32 & 0.92 & 17.9 & 17.2 & 53.1 & 53.4 \\
\hline \multirow{8}{*}{ Rib $2 \times 1$} & 10 & 1.04 & 1.68 & 1.74 & 11.9 & 8 & 43.2 & 40.1 \\
\hline & 11 & 1.01 & 1.52 & 1.54 & 12.4 & 8.2 & 45.1 & 42.2 \\
\hline & 12 & 0.92 & 1.44 & 1.32 & 13.8 & 9.1 & 45.2 & 44.1 \\
\hline & 13 & 0.81 & 1.41 & 1.14 & 14.2 & 9.6 & 47.7 & 49.2 \\
\hline & 14 & 0.91 & 1.38 & 1.26 & 15.2 & 10.7 & 48.9 & 49.1 \\
\hline & 15 & 0.87 & 1.26 & 1.09 & 15.7 & 16 & 49.3 & 50.4 \\
\hline & 16 & 0.83 & 1.2 & 0.99 & 16.3 & 17.1 & 50 & 51.4 \\
\hline & 17 & 0.79 & 1.17 & 0.92 & 16.7 & 18 & 51.3 & 51.6 \\
\hline \multirow{8}{*}{ Single jersey } & 13 & 1.18 & 1.48 & 1.75 & 11.9 & 21.9 & 44.2 & 47.2 \\
\hline & 14 & 1.16 & 1.44 & 1.67 & 13.1 & 22.6 & 45.3 & 48.1 \\
\hline & 15 & 1.12 & 1.42 & 1.6 & 13.6 & 24.6 & 47 & 48.7 \\
\hline & 16 & 1.08 & 1.4 & 1.51 & 14.1 & 25.2 & 51 & 49 \\
\hline & 17 & 1.06 & 1.38 & 1.46 & 14.4 & 27 & 51.3 & 49.1 \\
\hline & 18 & 0.98 & 1.3 & 1.27 & 16.6 & 34.5 & 53.5 & 49.6 \\
\hline & 19 & 0.86 & 1.28 & 1.1 & 17.2 & 35.5 & 54.9 & 53.4 \\
\hline & 20 & 0.62 & 1.2 & 0.74 & 18.6 & 36.5 & 55.2 & 54.1 \\
\hline
\end{tabular}

TABLE 4: Results of fabric geometry of single jersey, \% lux included (CKM samples).

\begin{tabular}{|c|c|c|c|c|c|c|c|c|}
\hline $\begin{array}{l}\text { Single jersey } \\
\text { sample }\end{array}$ & $\begin{array}{c}\text { Course per } \\
\text { inch }\left(K_{c}\right)\end{array}$ & $\begin{array}{l}\text { Wales per } \\
\text { inch }\left(K_{w}\right)\end{array}$ & $\begin{array}{c}\text { Stitch density } \\
\left(K_{s}\right)\end{array}$ & $\begin{array}{c}\text { Stitch } \\
\text { length, } l\end{array}$ & $\begin{array}{l}\text { Tightness } \\
\text { factor }\end{array}$ & $\operatorname{Lux}(\%)$ & $\begin{array}{c}\text { Porosity (black } \\
\text { mask) (\%) }\end{array}$ & $\begin{array}{c}\text { Porosity (white } \\
\text { mask) (\%) }\end{array}$ \\
\hline 1 & 4.8 & 6.5 & 31.2 & 3 & 2.86 & 11.4 & 44.4 & 47.2 \\
\hline 2 & 4.6 & 6.3 & 29 & 3.1 & 2.82 & 12 & 45 & 48.5 \\
\hline 3 & 4.4 & 5.8 & 25.5 & 3.3 & 2.73 & 13.8 & 49.5 & 49.1 \\
\hline 4 & 4.3 & 5.7 & 24.1 & 3.5 & 2.65 & 14.1 & 51.3 & 51.7 \\
\hline 5 & 4 & 5.6 & 25.1 & 3.6 & 2.68 & 14.9 & 51.5 & 49.6 \\
\hline 6 & 3.8 & 5.3 & 20.1 & 3.8 & 2.54 & 15.2 & 53 & 50.1 \\
\hline 7 & 3.7 & 5.1 & 18.9 & 3.9 & 2.51 & 16.5 & 53.8 & 51.2 \\
\hline 8 & 3.5 & 4.8 & 16.8 & 4.2 & 2.42 & 16.8 & 54.2 & 53.9 \\
\hline
\end{tabular}




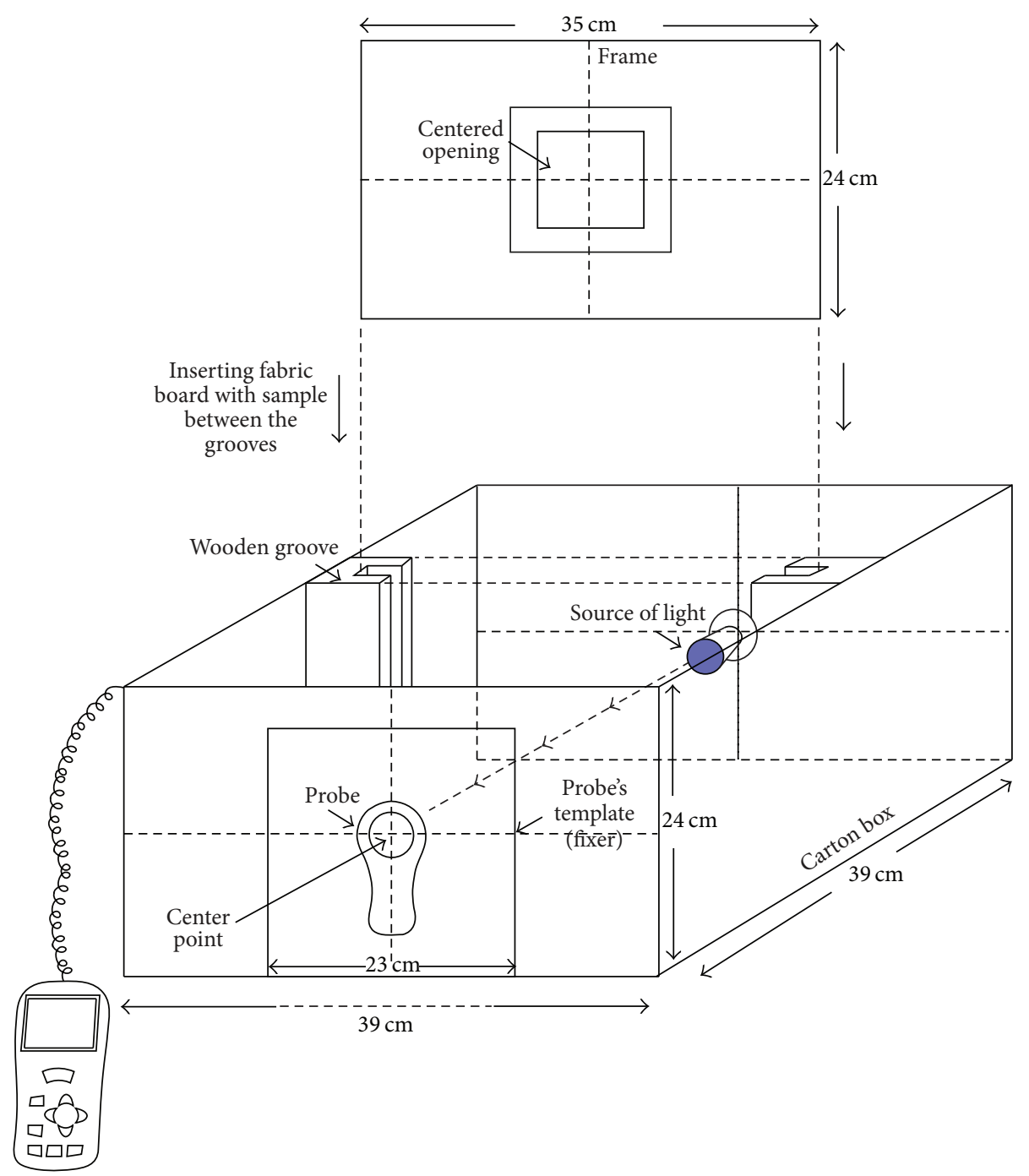

FIGURE 3: Schematic diagram of stand set-up.

Following are $R^{2}$ values for white mask images: plain: $R^{2}=$ 0.793 , rib $1 \times 1: R^{2}=0.609$, rib $2 \times 2: R^{2}=0.782$, and single jersey: $R^{2}=0.863$. It can be deduced that there is no strong relationship when calculating black masks compared to the white masks.

3.2.3. Validating Correlations and Regression (FKM). The verification of measurement was done on the assessment of convergence of yarn length in loop measurement results obtained from the measurement during realization of technological samples on the machine.

Tables 5 and 6 show the correlation values for the different parameters and experimental values involved for FKM knits.

3.3. Results for CKM Single Jersey Samples. The comparison analysis was also carried out on the CKM knitted single jersey samples. This activity was aimed at showing the difference in light permeability against the FKM knits.
TABLE 5: Linear regression equations-\% lux against stitch length (FKM samples).

\begin{tabular}{lcc}
\hline Fabric features & Structures & Linear regression equations \\
\hline & Plain & \% lux $=1.955(\mathrm{SL})-7.997$ \\
\% lux v/s stitch & Rib $1 \times 1$ & \% lux $=1.422(\mathrm{SL})-8.012$ \\
length (SL) & Rib $2 \times 1$ & \% lux $=2.178(\mathrm{SL})-19.54$ \\
& Single jersey & \% lux $=2.584(\mathrm{SL})-10.12$ \\
\hline
\end{tabular}

The percentage lux values increase with increasing stitch length due to increase in stitch density.

The values of stitch density calculated are given in Table 4. The values decrease from sample 1 to sample 8 because of the decrease in course count and in the wale count.

According to the values obtained for percentage lux, the percentage porosity was plotted against it. As shown, percentage lux increases with increase in percentage porosity. Regarding the FKM sample knits, as the tension on machine 
TABLE 6: Linear regression equations-\% porosity against \% lux (FKM samples).

\begin{tabular}{lccr}
\hline Fabric features & Structures & White masks & Black masks \\
\hline & Plain & $\% P=0.620(\%$ lux $)+42.31$ & $\% P=0.307(\%$ lux $)+45.39$ \\
\% porosity v/s \% lux & Rib $1 \times 1$ & $\% P=0.276(\%$ lux $)+46.71$ & $\% P=0.357(\%$ lux $)+46.38$ \\
& Rib $2 \times 1$ & $\% P=0.590(\%$ lux $)+40.44$ & $\% P=0.883(\%$ lux $)+36.58$ \\
& Single jersey & $\% P=0.662(\%$ lux $)+31.43$ & $\% P=0.366(\%$ lux $)+39.47$ \\
\hline
\end{tabular}

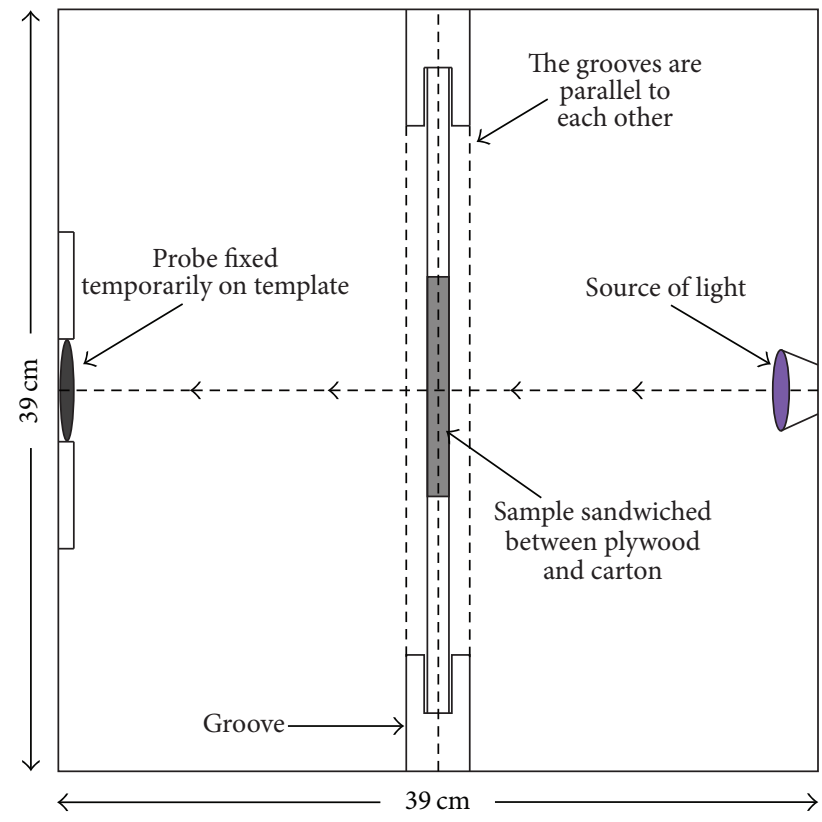

Figure 4: Top view of box.

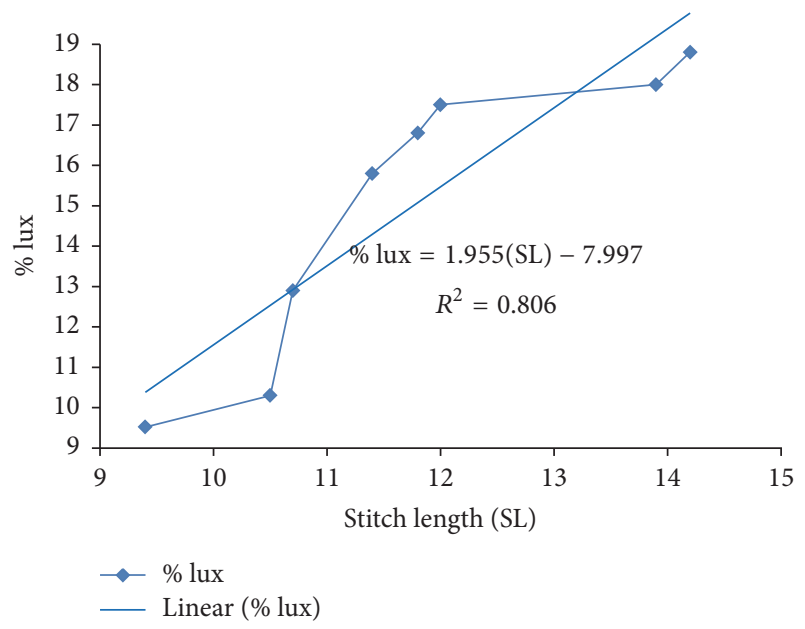

FIGURE 5: \% lux against stitch length for plain structure.

was carefully adjusted no variations in the trends were observed as shown in Figure 13.

By reviewing Figure 14, it is clear that the percentage lux increases with percentage porosity. The observation results show that the fabric samples 5 and 6 exhibit an anomaly. It was observed that sample 3 results in high percentage porosity;

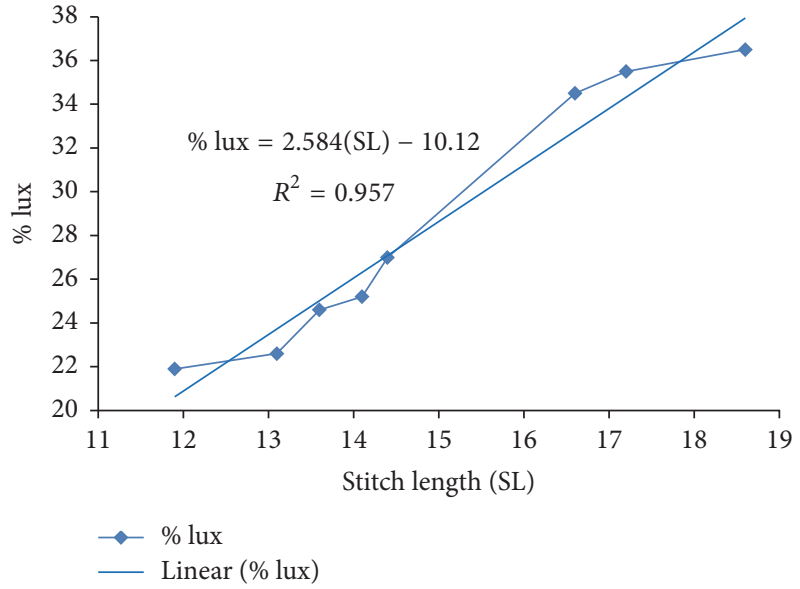

FIgURE 6: \% lux against stitch length for single jersey structure.

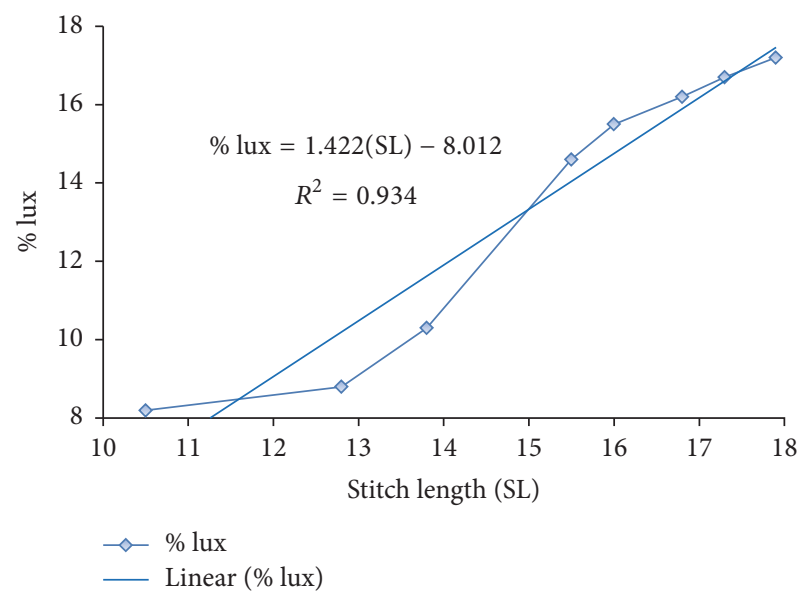

FIgURE 7: \% lux against stitch length for rib $1 \times 1$ structure.

thus it was plotted automatically after the fourth sample's data was plotted.

Table 4 shows that the stitch length and knitting parameters influence the percentage lux. This occurs as a result of the porosity of the knitted fabrics. The fact that with increasing stitch length and reducing tightness factor more knitted pores are created between the loops allows more light to pass through the knitted specimens.

Tightness factor is inversely proportional to percentage lux as shown in Figure 15. Generally, a higher increase is noted for sample 2 and the tendency decreases till sample 1 . The results shown in Table 4 indicate that the tightness factor has a significant effect on the stitch length. Tighter fabric reduces 


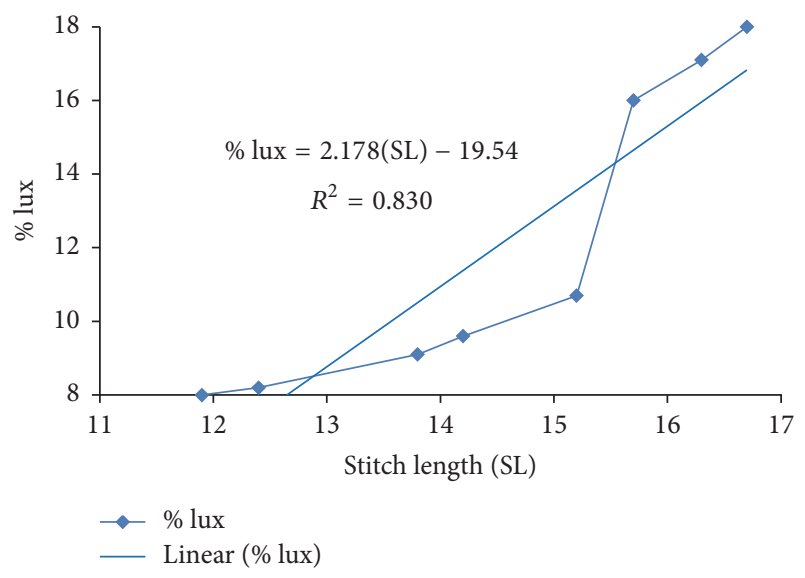

FIGURE 8: \% lux against stitch length for rib $2 \times 1$ structure.

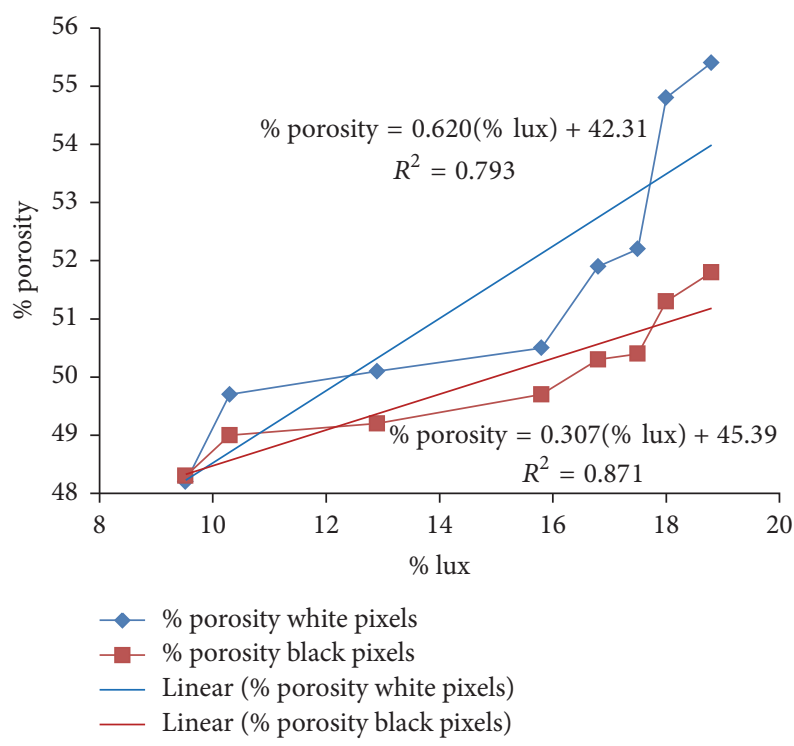

FIGURE 9: Percentage porosity against percentage lux for plain.

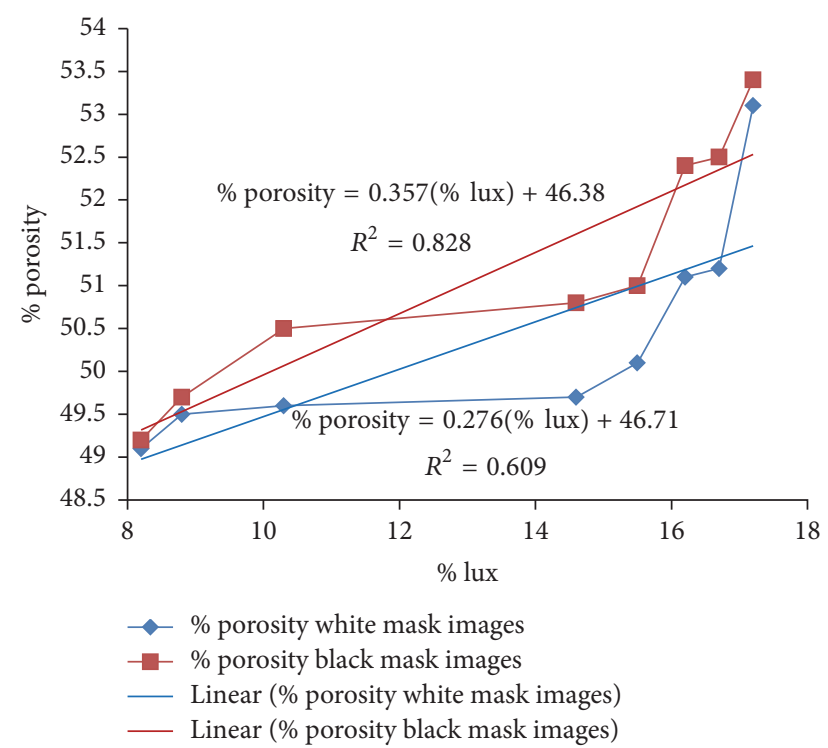

Figure 10: Percentage porosity against percentage lux for rib $1 \times 1$.

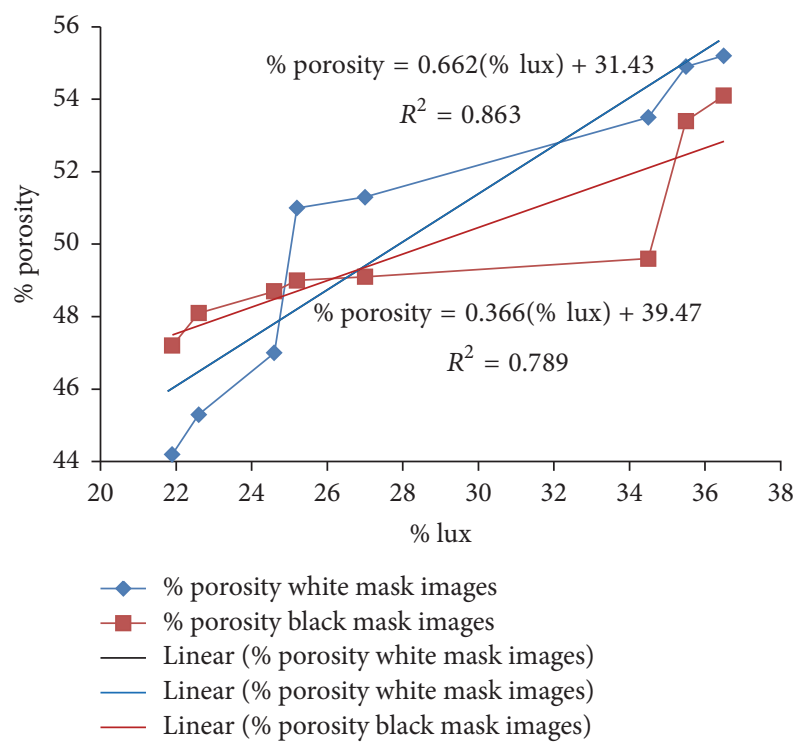

FIGURE 11: Percentage porosity against percentage lux for single jersey.

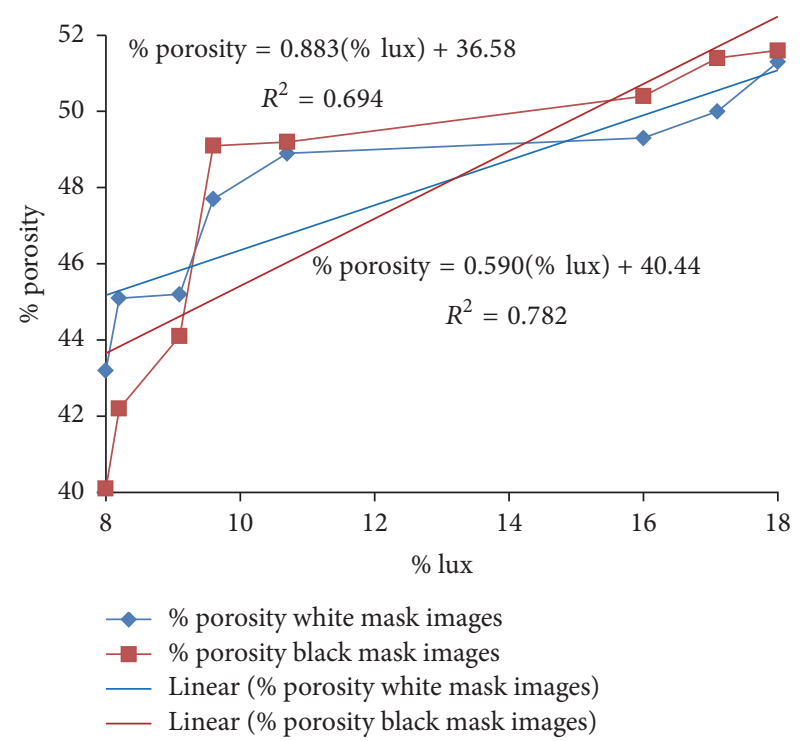

FIGURE 12: Percentage porosity against percentage lux for rib $2 \times 1$.

the light permeability of the fabric specimen. Similar result was observed in Figure 16 for percentage lux against stitch density.

Tables 7 and 8 show the correlation values for the different parameters and experimental values involved with CKM knits.

3.4. Experimental Results for the Structures for Validation (CKM). Two "fresh" samples were eventually used to confirm the regression analysis. The ninth and tenth knitted sample's geometry and image analysis results were determined using the same procedures as done for the former samples. 


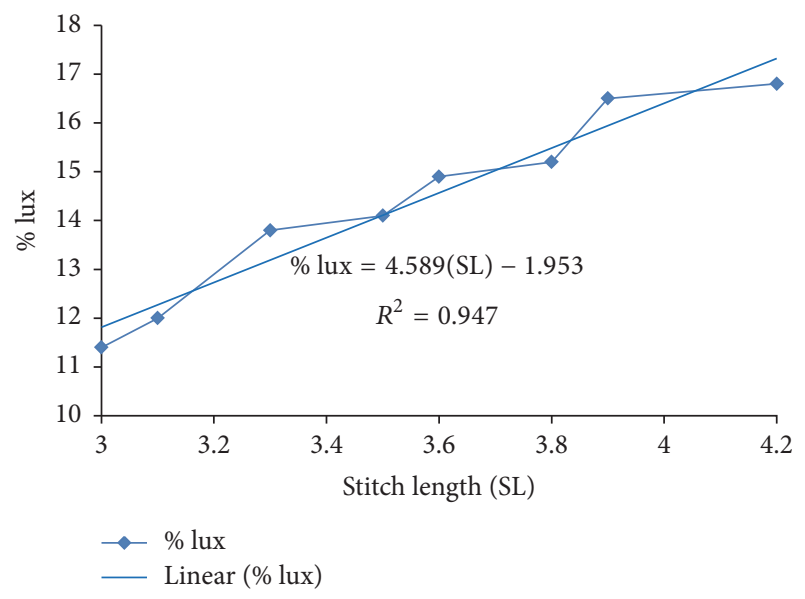

FIGURE 13: \% lux against SL.

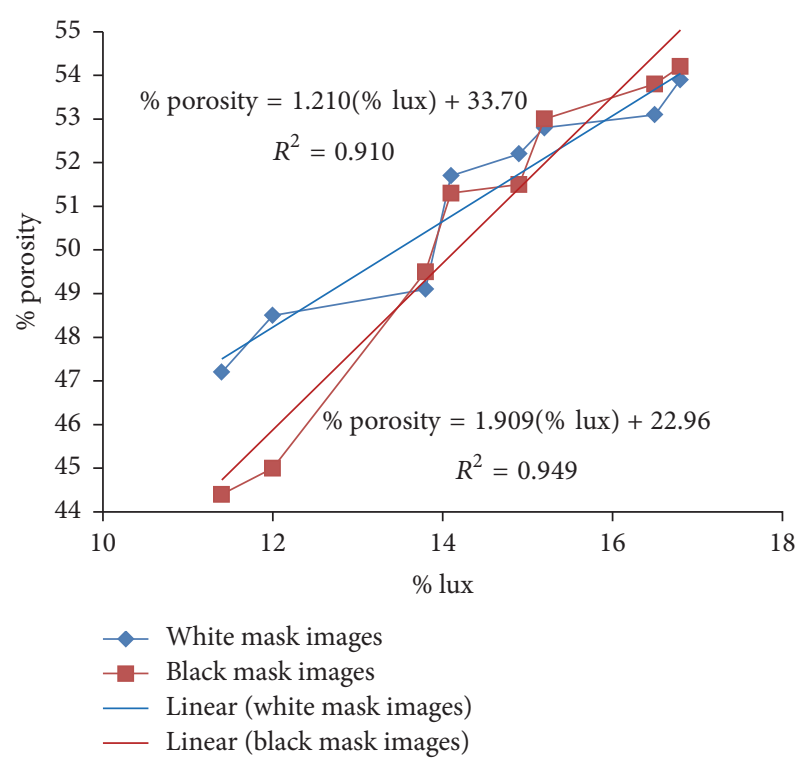

FIGURE $14: \%$ porosity against $\%$ lux.

TABLE 7: Linear regression equations for the fabric characteristics of the CKM knits.

\begin{tabular}{lc}
\hline Fabric features & Single jersey \\
\hline $\begin{array}{l}\text { Tightness factor v/s stitch } \\
\text { length (SL) }\end{array}$ & $\mathrm{TF}=-0.372(\mathrm{SL})+3.966$ \\
$\%$ lux v/s stitch length (SL) & $\% \operatorname{lux}=4.589(\mathrm{SL})-1.953$ \\
$\%$ lux v/s stitch density (SD) & $\% \mathrm{lux}=-0.385(\mathrm{sd})+23.45$ \\
\% lux v/s tightness factor & $\% \mathrm{lux}=-12.37(\mathrm{TF})+47.03$ \\
$(\mathrm{TF})$ &
\end{tabular}

3.5. Modeling. The model values of percentage lux and percentage porosity are calculated by substituting the knitting parameters in the equations in Tables 5, 6, 7, and 8. By calculation of the model values of the percentage porosity and percentage lux, the stitch length of the knitted fabrics is taken into consideration. This section also presents a comparison of the experimental and model values of the percentage porosity

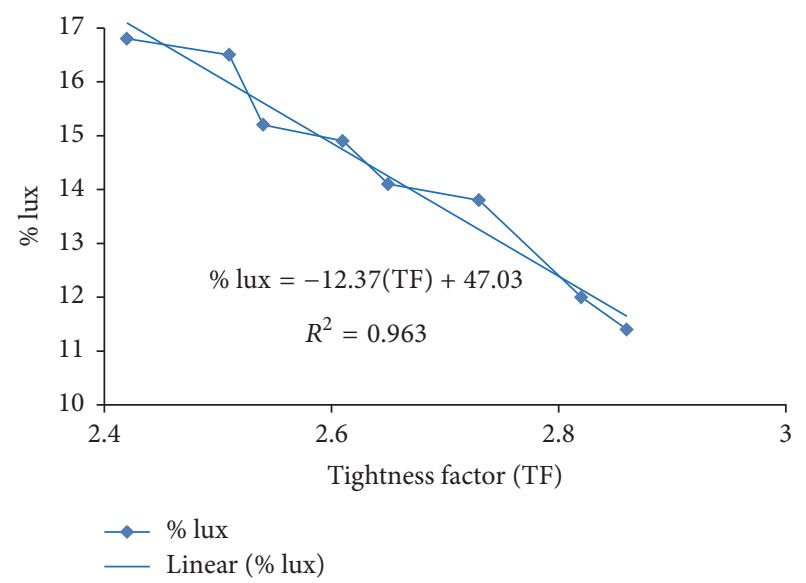

FIgURE 15: \% lux against TF.

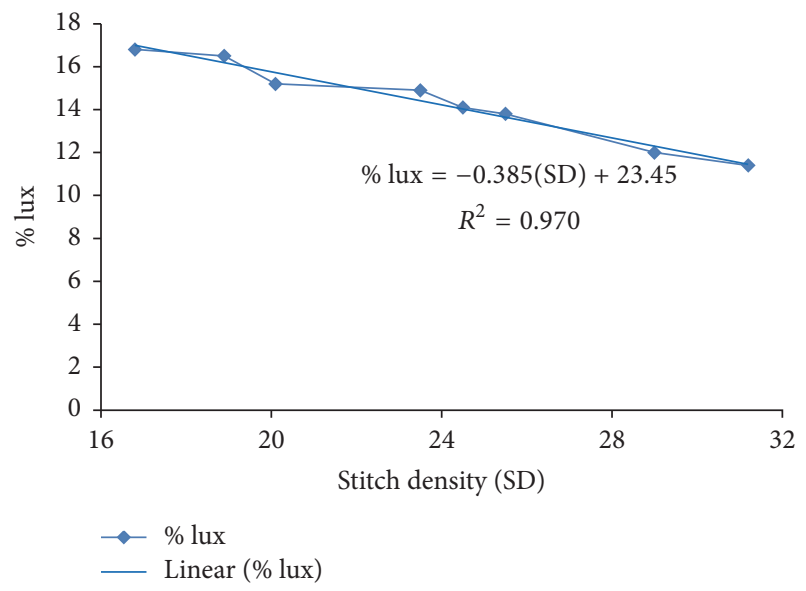

FIgURE 16: \% lux against SD.

TABLE 8: Linear regression equations for the fabric characteristics of the CKM knits.

\begin{tabular}{lcc}
\hline \multirow{2}{*}{ Fabric features } & \multicolumn{2}{c}{ Single jersey } \\
& White mask & Black mask \\
\hline$\%(P)$ v/s \% lux & $\begin{array}{c}\text { 1.210 }(\% \text { lux })+ \\
33.70\end{array}$ & $\% P=$ \\
& $1.909(\%$ lux $)+22.96$ \\
\hline
\end{tabular}

and percentage lux. The percentage error was calculated using the following equation:

Percentage Error (\%)

$$
\begin{aligned}
= & {\left[\frac{\text { Model Values }- \text { Measured Values }(\text { Experimental })}{\text { Measured Values }(\text { Experimental })}\right] } \\
& \times(100 \%)
\end{aligned}
$$

Tables 9 and 10 show the calculated percentage error for the CKM knitted samples whereas Table 11 shows result for validation of the FKM samples and in Table 12 the estimated model data for $\%$ lux are calculated. 
TABLE 9: Experimental values, model values, and percentage error for the knitted sample and relating them to the features (FKM samples).

\begin{tabular}{|c|c|c|c|c|c|c|}
\hline Structures & Stitch cam values & Stitch density $\left(K_{s}\right)$ & Stitch length, $l(\mathrm{~mm})$ & Expt. percentage lux (\%) & Model values & Error \\
\hline \multirow{2}{*}{ Plain } & 19 & 0.45 & 15.1 & 19.5 & 21.5 & 10.3 \\
\hline & 20 & 0.41 & 15.7 & 20 & 22.7 & 13.5 \\
\hline \multirow{2}{*}{ Rib $1 \times 1$} & 19 & 0.88 & 18.8 & 18.4 & 18.7 & 1.63 \\
\hline & 20 & 0.83 & 19.5 & 19.1 & 19.7 & 3.14 \\
\hline \multirow{2}{*}{ Rib $2 \times 1$} & 18 & 0.59 & 17.6 & 19.9 & 18.8 & -5.5 \\
\hline & 19 & 0.46 & 18.9 & 20.8 & 21.6 & 3.85 \\
\hline \multirow{2}{*}{ Single jersey } & 21 & 0.5 & 19.9 & 38.3 & 41.3 & 7.83 \\
\hline & 22 & 0.46 & 22 & 40 & 46.7 & 16.8 \\
\hline
\end{tabular}

TABLE 10: Experimental values, model values, and percentage error for the porosity of white and black mask for \% porosity and lux (FKM samples).

\begin{tabular}{|c|c|c|c|c|c|c|c|c|}
\hline Structures & $\begin{array}{l}\text { Stitch cam } \\
\text { values }\end{array}$ & $\begin{array}{l}\text { Percentage } \\
\text { lux }(\%)\end{array}$ & $\begin{array}{c}\text { Expt. } \\
\text { porosity } \\
\text { (white mask) } \\
(\%)\end{array}$ & $\begin{array}{c}\text { Expt. } \\
\text { porosity } \\
\text { (black mask) } \\
(\%)\end{array}$ & $\begin{array}{l}\text { Model porosity } \\
\text { (white mask) (\%) }\end{array}$ & $\begin{array}{c}\text { Model porosity } \\
\text { (black mask) }(\%)\end{array}$ & $\begin{array}{c}\% \text { error } \\
\text { (white mask) }\end{array}$ & $\begin{array}{c}\% \text { error } \\
\text { (black mask) }\end{array}$ \\
\hline \multirow{2}{*}{ Plain } & 19 & 19.5 & 55.8 & 52.1 & 54.4 & 51.4 & -2.5 & -1.34 \\
\hline & 20 & 20 & 56.9 & 52.2 & 54.7 & 51.5 & -3.87 & -1.34 \\
\hline \multirow{2}{*}{ Rib $1 \times 1$} & 19 & 18.4 & 54.9 & 55 & 51.8 & 52.9 & -5.65 & -3.81 \\
\hline & 20 & 19.1 & 56 & 55.8 & 52 & 53.2 & -7.14 & -4.66 \\
\hline \multirow{2}{*}{ Rib $2 \times 1$} & 18 & 19.9 & 53 & 52.7 & 52.2 & 54.2 & -1.51 & 2.85 \\
\hline & 19 & 20.8 & 53.8 & 54.7 & 52.7 & 55 & -2.04 & 0.55 \\
\hline \multirow{2}{*}{ Single jersey } & 21 & 38.3 & 57.6 & 57.2 & 56.8 & 53.5 & -1.39 & -6.47 \\
\hline & 22 & 40 & 59.9 & 58.8 & 58 & 54.1 & -3.17 & -7.99 \\
\hline
\end{tabular}

TABLE 11: Experimental values for validation of tested CKM samples.

\begin{tabular}{|c|c|c|c|c|c|c|}
\hline $\begin{array}{l}\text { Single jersey } \\
\text { sample }\end{array}$ & Stitch density $\left(K_{s}\right)$ & Stitch length, $l$ & Tightness factor & $\begin{array}{l}\text { Porosity (white } \\
\text { mask) (\%) }\end{array}$ & $\begin{array}{c}\text { Porosity (black } \\
\text { mask) }(\%)\end{array}$ & $\operatorname{Lux}(\%)$ \\
\hline 9 & 14.1 & 4.6 & 2.31 & 55.4 & 55.1 & 18.2 \\
\hline 10 & 14.6 & 4.8 & 2.26 & 56.2 & 57.3 & 19.8 \\
\hline
\end{tabular}

A positive percentage error indicates that the experimental value is too high while a negative percentage error indicates that the experimental value is too low. The impact of knitting parameters on porosity and lux is evident. It is already known that light permeability also relies on the configuration of the knitted fabrics, that is, the structure of the interthread spaces forming the loops, commonly known as the pores. Moreover, it must be highlighted that light permeability is connected to the fabric's tightness or looseness and other knitting parameters. The percentage error is lower for the single jersey fabric, as shown in Table 13. The FKM single jersey structures expose larger number of pores in the fabric than the other knits. From Table 10, it should be taken into account that the percentage error for all white mask images is negative. It would therefore be more plausible to derive porosity data from the black mask values. Similar observations can be made for the comparison of \% porosity against \% lux. Analysis of the light permeability of single jersey structures is useful when designing summer wear garments. The differences in percentage error are higher for black masks than white masks. The percentage of black masks shows higher significance for the light permeability.

\section{Conclusion}

As a result of research, it is seen that the light permeability of fabric knitted at different tensions and machine settings vary greatly. Light permeability has a direct relationship with the tightness of the fabric. The stitch length, tightness factor, and porosity affect the light permeability property of knitted fabrics. In addition, it has also been deduced from the regression analysis that tightness factor can be used for fabric light permeability forecasting. This has been confirmed due to the high correlation between the light permeability and tightness factor. The values of light permeability increase due to increasing stitch length. It was observed that dependencies exist between the light permeability and porosity including knitting parameters. This is due to the fact that both quantities depend on the structure of the knitted fabrics, especially the stitch length and the tension on machine. Light 
TABLE 12: Estimated model data for \% lux, making \% lux the subject of formula in equation in Table 8 .

\begin{tabular}{lccccccc}
\hline \multirow{2}{*}{$\begin{array}{l}\text { Fabric features } \\
\text { Samples }\end{array}$} & Masking & Expt. value lux (\%) & Expt. value (\% porosity) & \multicolumn{2}{c}{ Model values for \% lux } & \multicolumn{2}{c}{ \% error for lux } \\
\hline \% lux, \% & & & 9 & 10 & 9 & 10 & 9 \\
porosity & White & 18.2 & 55.4 & 56.2 & 18.1 & 18.6 & -0.55 \\
\hline
\end{tabular}

TABLE 13: Estimated model data for \% lux of CKM knits against fabric features.

\begin{tabular}{|c|c|c|c|c|c|c|}
\hline \multirow{3}{*}{$\begin{array}{l}\text { Fabric features } \\
\text { Samples }\end{array}$} & \multicolumn{6}{|c|}{ Single jersey } \\
\hline & \multicolumn{2}{|c|}{ Expt. value (\% lux) } & \multicolumn{2}{|c|}{ Model values } & \multicolumn{2}{|c|}{$\%$ error $(\%)$} \\
\hline & 9 & 10 & 9 & 10 & 9 & 10 \\
\hline \% lux v/s (SL) & 18.2 & 19.8 & 19.1 & 20 & 4.9 & 1.01 \\
\hline \% lux v/s (SD) & 18.2 & 19.8 & 18 & 17.8 & -1.09 & -10.1 \\
\hline \% lux v/s (TF) & 18.2 & 19.8 & 18.5 & 19.1 & 1.65 & -3.54 \\
\hline
\end{tabular}

permeability variations of the knitted structures are caused by the hairiness of the thread and twist, as well as the stitch density. Light permeability can therefore be assigned to the UV transmission through clothing as sunrays contain UV light that would directly affect the skin. The focus in this study was the investigation of porosity and light permeability. The fabric weight and fabric thickness will also be considered for UV measurement for further work. A stand set-up was engineered so as to specifically measure the light transmission through different knitted samples. There are various practical applications from the result of this study. Potential future research projects in this area are, for example, development of simulation from bioinspired anti-UVR features. Considering the changing nature of technology, development of $3 \mathrm{D}$ models of knitted fabrics geometry may also be included. The structural parameters may be considered to be varied in relation to bioinspired structures. Another interesting field of research is virtual reality (VR) and augmented reality (AR). For real time application it may be interesting to study $A R$ as the development of an interactive AR application to measure UPF of fabrics can be considered. Such an effort would enable any user to consider getting UPF measurement of a garment when shopping.

\section{Competing Interests}

The authors declare that there is no conflict of interests regarding the publication of this paper.

\section{References}

[1] D. Hanke, K. Hoffman, A. Altmeyer et al., "UV protection by textiles," Chemical Fibers International, vol. 47 , no. 4, pp. 130131, 1997.

[2] W. Jędrzejewski, H. Królikowska, K. Kader, and J. Perkowski, "Barrier properties against noxious impact of UV radiationsummer ready-made woven fabrics," Przegląd Włókienniczy, vol. 52, no. 11, pp. 17-20, 1998 (Polish).
[3] H. Gabijelcic and R. Urbas, "Influence of fabric constructional parameters and the thread colour on UV radiation protection," Fibres and Textile in Eastern Europe, vol. 17, no. 1(72), pp. 46-54, 2009.

[4] Y. Yazaki, M. Takatera, and Y. Shimizu, "Light transmission properties of plain knitted fabrics in uniaxial and biaxial extension," Sen'i Gakkaishi, vol. 61, no. 7, pp. 183-190, 2005.

[5] Y. Yazaki, M. Takatera, and Y. Shimizu, "Anisotropic light transmission properties of plain woven fabrics," Sen'i Gakkaishi, vol. 60, no. 10, pp. 281-286, 2004.

[6] A. Nazir, T. Hussain, A. Afzal, S. Faheem, W. Ibrahim, and M. Bilal, "Prediction and correlation of air permeability and light transmission properties of woven cotton fabrics," Autex Research Journal, 2016.

[7] N. Haleem, S. Ibrahim, T. Hussain, A. Jabbar, M. H. Malik, and Z. A. Malik, "Determining the light transmission of woven fabrics through different measurement methods and its correlation with air permeability," Journal of Engineered Fibers and Fabrics, vol. 9, no. 4, pp. 76-82, 2014.

[8] J. Militky, M. Travnickova, and V. Bajzik, "Air permeability and light transmission of weaves," International Journal of Clothing Science and Technology, vol. 11, no. 2-3, pp. 116-125, 1999.

[9] M. S. Parmar, N. Sisodia, and M. Singh, "An apparatus for quantification of light and temperature cutting ability of curtains," Indian Journal of Fibre \& Textile Research, vol. 40, pp. 231-235, 2015.

[10] X. Cui, Q. F. Ke, and G. M. Cai, "Evaluation of light protective properties of high performance aramid fabrics," Applied Mechanics and Materials, vol. 551, pp. 28-31, 2014.

[11] Z. Mikolajczyk and J. Szmyt, "Light transmission through decorative knitted fabrics in correlation with their fabric cover," AUTEX Research Journal, vol. 10, no. 2, 2010.

[12] I. Algaba, A. Riva, and P. C. Crews, "Influence of fiber type and fabric porosity on the UPF of summer fabrics," AATCC Review, vol. 4, no. 2, pp. 26-31, 2004.

[13] J. Bransch-Walczak and A. Jemielity, Kształtowanie Obrazu w Fotografii, Pracownia Technik Fotografii, PTF, 1998.

[14] W. Dederko, Warsztattechnicznyartystyfotografa, COK, Warszawa, 1985. 
[15] M. Dulęba-Majek, Comparative Analyses of UV Radiation Transmission through Virtual and Real Woven Fabrics for Selected Weaves, Textile Research Institute, Łódź, Poland, 2009.

[16] A. Ullman, Triki w Fotografii, Wydawnictwa Naukowo-Techniczne, Warszawa, Poland, 1975. 

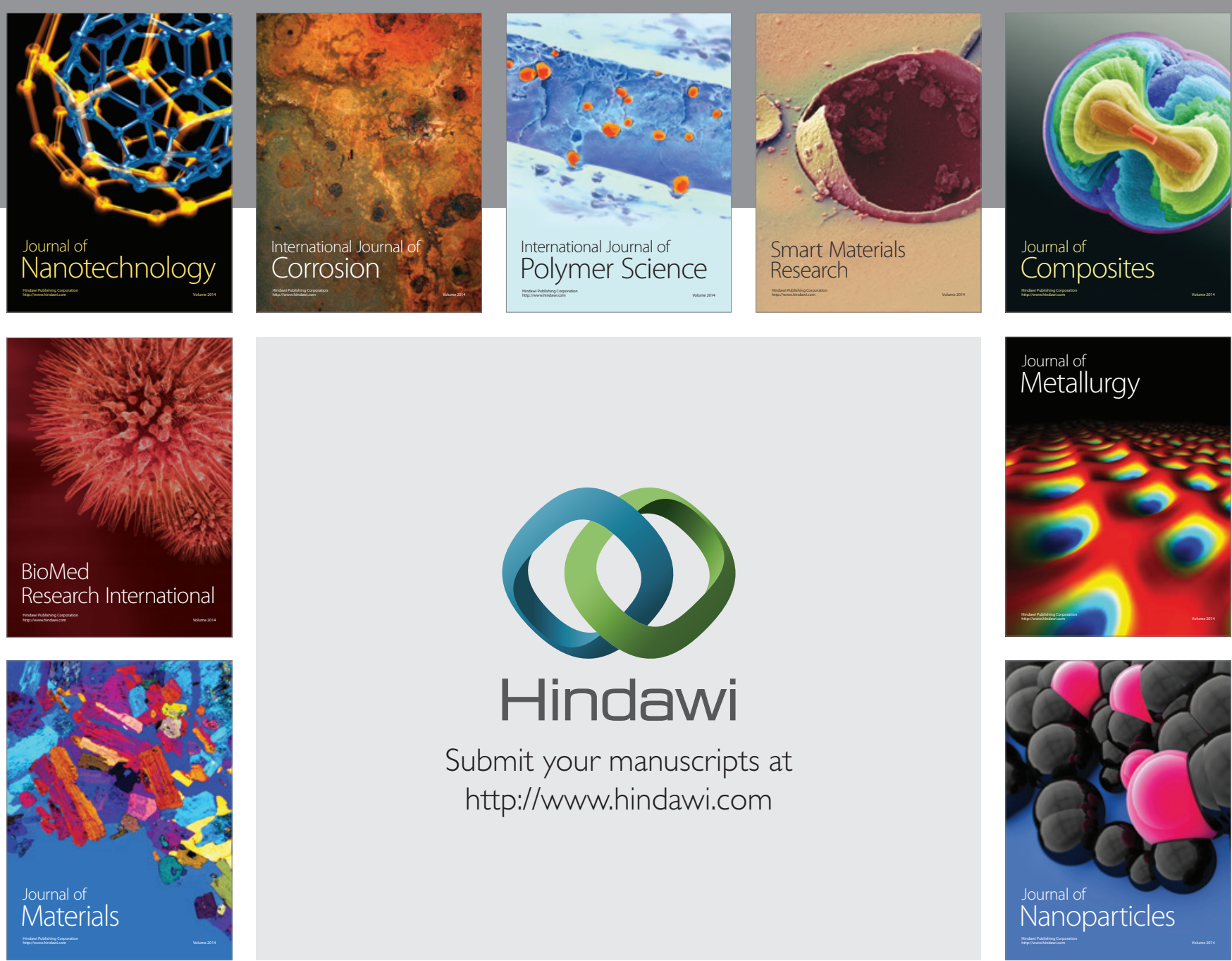

\section{Hindawi}

Submit your manuscripts at

http://www.hindawi.com

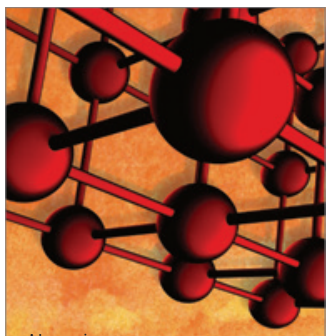

Materials Science and Engineering
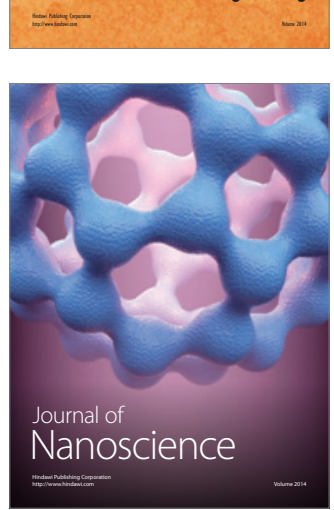
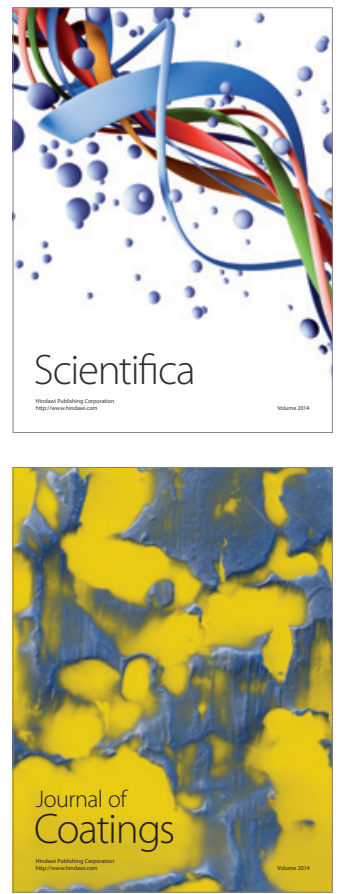
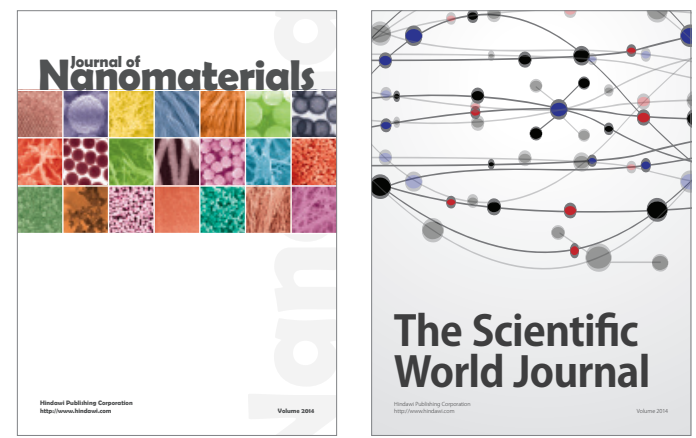

The Scientific World Journal
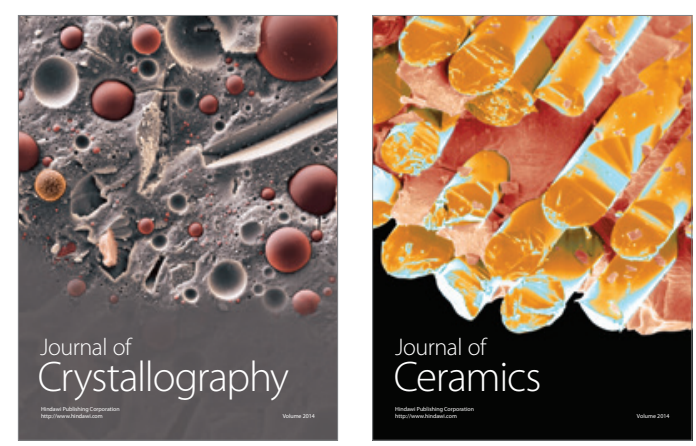
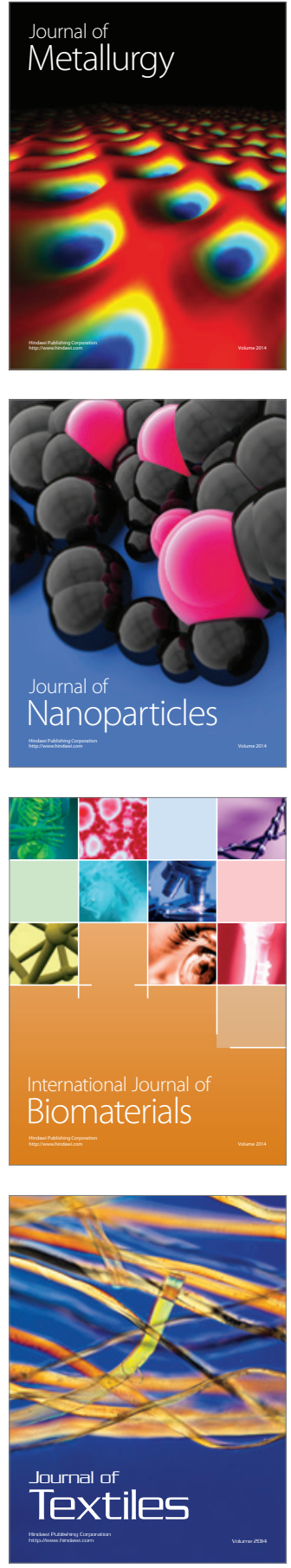